\title{
Obesity and Vitamin D Deficiency - Current Concepts on their Impact on Pregnancy
}

\author{
Trixie McAree
}

Consultant Midwife, North West London Hospitals NHS Trust, Harrow, UK

\begin{abstract}
Both obesity and vitamin D deficiency are linked to morbidity and ultimately mortality. Vitamin D sufficiency is believed to confer many health benefits; however, with the exception of the classic functions related to bone health these are not yet well understood, especially in relationship to pregnancy and infant health outcomes. ${ }^{1}$ Conversely, insufficiency is associated with adverse health outcomes, which are consequently related to public health concerns that arise from these and these need addressing. ${ }^{2,3}$ While the links between health and vitamin $\mathrm{D}$ are being considered and researched, there are an increasing number of reports that demonstrate vitamin $\mathrm{D}$ deficiency is prevalent particularly among people who are darker skinned, those who live at latitudes above $52^{\circ}$, and are therefore exposed to reduced sunlight especially in the autumn and winter months, those who through lifestyle choices cover their bodies, preventing sunlight exposure, and in obese people. .-6 $^{3-}$ besity is also of growing concern. Health journalists and academics sometimes dramatically refer to 'obesity epidemics,' which is not surprising as over one-third of Americans are obese.-9 This problem, if not addressed, will lead to adverse health outcomes for individuals as well as being a long-term burden both to families and society. ${ }^{10-11}$ It is interesting to note that both vitamin D deficiency and obesity have shared risks for mortality and morbidity including cardiovascular disease, diabetes, respiratory problems, cancer and musculoskeletal disease. This paper considers current concepts and the links between obesity and vitamin D deficiency in pregnancy seeking to determine whether being vitamin D deficient and obese is simply double trouble, where both are present, or whether there are there other factors that need further exploration, reviewing the associated implications for practice. ${ }^{12-15}$
\end{abstract}

\section{Keywords}

Vitamin D, obesity, pregnancy

\section{Disclosure: The author has no conflicts of interest to declare.}

Received: 8 April 2013 Accepted: 13 May 2013 Citation: European Endocrinology 2013;9(2):125-7 DOI:10.17925/EE.2013.09.02.125

Correspondence: Trixie McAree, Consultant Midwife, North West London Hospital Trust, Northwick Park Hospital, Watford Road, Harrow, HA1 3UJ, UK. E: trixie.mcaree@nhs.net

\section{Background and Literature Review}

Obesity in pregnancy carries risks. Raja et al. ${ }^{16}$ carried out a review of deliveries between January 2002 and December 2007. Obese mothers (body mass index $[\mathrm{BMI}] \geq 30$ ) were shown to be at significantly higher risk from multiple morbidities $(p<0.05)$, including gestational diabetes; antepartum haemorrhage; preterm delivery before 37 and 33 weeks of gestation; induction of labour; analgesia use (beyond inhalational methods and local infiltration); caesarean sections; massive postpartum haemorrhage; higher birthweights; and a greater need for neonatal care (special care baby unit [SCBU], high-dependency unit [HDU] and neonatal intensive care unit [NICU]) compared with mothers with a BMI <30. These findings add to the growing consensus that obesity increases the risks involved with pregnancy. ${ }^{17-18}$

Furthermore, it has been reported that obese pregnant women have an increased use of healthcare services, especially for $\mathrm{BMI}>35,{ }^{19}$ increased caesarean section rate ${ }^{20}$ and increased risk of infant mortality, both of which may involve cardiometabolic morbidity. ${ }^{21}$ Catalano ${ }^{22}$ suggests that this may be related to a decrease in insulin sensitivity, and therefore overweight and obese women are at increased risk of metabolic dysregulation in pregnancy, i.e. gestational diabetes, preeclampsia and foetal overgrowth.

The presence of vitamin D in sufficient quantities is thought to modify the risk of adverse cardiometabolic outcomes, ${ }^{23,24}$ although the association remains unclear. ${ }^{25}$ Vitamin $D$ is also thought to play an important role in insulin resistance and glucose homeostasis ${ }^{26}$ and it has been proposed that vitamin D supplementation may be an effective addition to the standard treatment of obesity and its associated insulin resistance. ${ }^{27}$

A couple of decades ago, four small studies ${ }^{28}$ suggested that obese subjects have higher 1,25-dihydroxy vitamin D (1,25-vit D) serum concentrations than non-obese controls. There are also studies that support the theory that 1,25 -vit $\mathrm{D}$ simulates lipogenesis. ${ }^{28}$ In an animal study, ${ }^{29}$ mice with knocked-off vitamin D receptors had smaller subcutaneous and visceral white adipose tissue depots, furthermore these mice were also resistant to high-fat diet-induced weight gain. Parihk ${ }^{28}$ tested the hypothesis that obesity is linked to higher levels of circulating $25(\mathrm{OH}) \mathrm{D}$ using a large subject group of healthy individuals. The result was that non-obese participants had almost twice as much circulating $25(\mathrm{OH})$ D as the obese subjects. It would seem obese individuals are at a greater risk of vitamin $D$ deficiency because vitamin $D$ is thought to be sequestered by excess adipose tissue not because as originally suggested that they do not like to go out in the sun. ${ }^{30}$

Although pregnancy does not appear to effect bioavailability of vitamin $D,{ }^{31}$ MCAree et al. ${ }^{3}$ found that obese pregnant women were more likely than non-obese women to have inadequate levels of $25(\mathrm{OH}) \mathrm{D}$ in pregnancy. This has been reported in previous studies and may be 
related to decreased bioavailability of vitamin $\mathrm{D}$ from cutaneous stores or its deposition in body fat. ${ }^{30}$ Bodnar et al. ${ }^{32}$ noted that there is a twofold increase in maternal and neonatal vitamin $D$ deficiency as maternal BMI increases from 22 to $34 \mathrm{~kg} / \mathrm{m}^{2}$. She was able to demonstrate the link between foetal and maternal serum $25(\mathrm{OH}) \mathrm{D}$, which is significant for the health of infants.

It has been suggested that the presence of nuclear vitamin $D$ receptors and of the vitamin D-activating 1-a-hydroxylase enzyme in the placenta and the decidua means that vitamin $\mathrm{D}$ acts as a modulator of foetal-placental development and function ${ }^{33}$ and is coupled with pregnancy progression, as well as playing a part in placental insufficiency and its sequela in foetal and maternal wellbeing during pregnancy. Vitamin D deficiency is associated with an increased caesarean section rate, $^{34,35}$ preeclampsia, ${ }^{36}$ low birthweight, ${ }^{1,2}$ bacterial vaginosis, ${ }^{1,2}$ and, in the presence of both obesity and vitamin D deficiency, the problem of gestational diabetes is increased. ${ }^{32}$ This clearly demonstrates the need for pregnant women to be vitamin $\mathrm{D}$ replete despite a recent Cochrane review $^{37}$ that suggests there is not sufficient data or robust enough studies with sufficient power to make absolute conclusions. However, vitamin D deficiency in pregnancy has been recognised as a serious concern for pregnant women especially if they are dark skinned or obese. ${ }^{3-5,32}$

It would seem that, although $25(\mathrm{OH}) \mathrm{D}$ deficiencies and obesity are associated and that vitamin D levels are likely to be lower to the point of being pathological when an individual is obese, any further mechanisms of cause or association are not yet understood. These are clearly matters that need to be dealt with from both an individual and population perspective.

\section{Implications for Practice}

Efforts to tackle the problems highlighted above have been hampered by the lack of high-quality evidence and thus it is difficult for clinicians to undertake any large-scale population or individual deficiency prevention programmes. ${ }^{5,37,38}$ The scale of the problem for pregnant women is now becoming clearer, and there are an unacceptable number of women with vitamin D deficiency. ${ }^{38}$ The report of Bodnar et al. ${ }^{32}$ of prepregnancy BMI in relation to gestational and cord $25(\mathrm{OH}) \mathrm{D}$ levels suggest that adiposity around conception may predict pregnancy and neonatal vitamin D status. Therefore there are clear markers available to see who are at greatest risk (i.e. those who are obese and those who have darker skin) and advice may be given according to government recommendations (The UK and US have different recommendations). However, details of interventions remain unclear and evidence regarding timing and optimal dosing for supplementation during pregnancy is lacking., ${ }^{5,38}$

The majority of vitamin $D$ is obtained through exposure of the skin to sunlight (ultraviolet B-[UV-B] light in the range 270-290 nm). At this wavelength, 7-dehydrocholesterol in skin is converted to previtamin $\mathrm{D}$, which isomerises to vitamin D3 and is then metabolised by the body to its active and inactive metabolites. ${ }^{39}$ Although advising pregnant women to expose themselves to the sunlight by going for walks, which would enhance both vitamin D status and general fitness thus tackling obesity, their lifestyle needs to be taken into consideration. For example, some cover up their whole bodies for religious reasons. Also in the Northern hemisphere the weather is not always amenable to such activity. Also, prolonged exposure to the sun is not without risks as it is associated with eye and skin disease. Furthermore, modern living means people spend more time indoors and engage in activities, such as watching television and computer-based activities, ${ }^{32}$ thus reducing natural exposure to the sun and reducing its potential to ameliorate vitamin D deficiency.

Vitamin D may be obtained from the diet, through the ingestion of oily fish, certain fortified foods and vitamin D supplements, and ingested vitamin $\mathrm{D}$ is metabolised in the same manner as that endogenously produced. Cross-sectional studies suggest that current US/Canadian fortification practices are not effective in preventing hypovitaminosis $D$, particularly among vulnerable populations during the winter, whereas supplement use shows more promise. ${ }^{40}$

It would appear modern living has precluded, to some degree, people naturally acquiring vitamin $\mathrm{D}$. Wortman et al..$^{30}$ conducted experiments with full body irradiation and oral vitamin D supplementation. They tested to evaluate the blood concentrations of vitamin $D$ in obese and non-obese subjects in response to UV-B irradiation or an oral dose of vitamin D2. He also performed studies in vitro to determine whether obesity affects the cutaneous production of vitamin D3. His results showed no difference between non-obese and obese individuals in the capacity of the skin to synthesise D3. However, the increase in blood vitamin D3 concentrations was 57 \% less in the obese than in the non-obese subjects 24 hours after the exposure. Thus, obesity did not affect the capacity of the skin to produce vitamin D3, but may have altered the release of vitamin D3 from the skin into the circulation. These data suggest that the availability of excessive adipose tissue causes a decrease in endogenously synthesised D3 to be released into circulation. Orally ingested vitamin D was more bioavailable and therefore suggests that vitamin D deficiency in obesity can be corrected by oral supplementation rather than using sunlamps.

The US National Institute for Health and the Endocrine Society ${ }^{41}$ recommend that most people will be at optimum levels of vitamin D at $50 \mathrm{nmols} / \mathrm{l}$ and that in pregnancy the optimal daily recommended allowance is $600 \mathrm{IU}$ or $15 \mathrm{mcg}$. In the UK this stands at $400 \mathrm{IU}$ daily. Consideration needs to be given as to how very deplete women, often the obese, will reach adequate levels. One study ${ }^{31}$ involving giving a one-off dose of 70,000 IU reported an increase in $25(\mathrm{OH}) \mathrm{D}$ levels that surged and then returned to normal. It would seem this is may act as a boost to $25(\mathrm{OH}) \mathrm{D}$ levels, but a maintenance dose would be required thereafter. Yu et al. ${ }^{42}$ undertook a study of supplementing women from 27 weeks of gestation, but did not achieve $25(\mathrm{OH}) \mathrm{D}$ levels of over $42 \mathrm{nmol} / \mathrm{l}$. Although all women and umbilical cord blood demonstrated a significantly higher level than the no treatment arm, $25(\mathrm{OH}) \mathrm{D}$ levels had not reached sufficiency. Neither of these studies took into consideration women's BMI and how this would influence dosing quantities.

Public and professional education requires further work as repeated studies demonstrate that neither women nor the professionals caring for them have a great awareness of the implications of vitamin $D$ deficiency. ${ }^{3}$

In many National Health Service guidance documents, managing prepregnancy conditions such as obesity and diabetes are recommended, but often there is limited provision for such a service. Preconceptual care would help to improve general health and maybe afford some weight loss prior to pregnancy and well as individuals gaining insight and perhaps enthusiasm for a healthier lifestyle. It has been demonstrated in a systematic review ${ }^{43}$ covering nine randomised controlled trials from 1966 to June 2006 that, although the trials were small and imperfect, they evidenced that vitamin D fortification 
improved vitamin D status in adults. Therefore in areas such as the UK, where there is limited food fortification, this should be considered as an adjunct to other measures to ensure pregnant women and infants have vitamin D sufficiency.

\section{Conclusion}

The discovery of vitamin $D$ and the subsequent near elimination of rickets must rank as one of medicine's great achievements, ${ }^{44}$ however, almost 100 years later, science is still grappling to understand and ascertain the implications of vitamin D deficiency. Therefore, it is difficult to make recommendations for health practitioners to follow when they give advice about supplementation particularly during pregnancy. It is clear from inferences gained from the research to date that pregnant woman who are both obese and vitamin $\mathrm{D}$ deficient should not only be concerned about their own health but that of their offspring and that having sufficient vitamin D will improve their long term health outlook.

Interventions in this area, once more clearly understood, will improve intergenerational health and prenatal conditions, which are of vital importance, 22,45 and surely this will involve further research, preconceptual care, and a population-wide public health intervention such as universal supplementation of vitamin D during pregnancy.
Thorne-Lyman A, Fawzi WW, Vitamin D During Pregnancy and Maternal and Infant Health Outcomes: A Systematic Review and Meta-analysis Paediatric and Perinatal Epidemiology, Paediatr Perinat Epidemiol, 2012:26 Suppl. 1:75-90.

Aghajafari F, Nagulesapilli T, Ronksley P, et al., Association between maternal serum 25 -hydroxyvitamin D level and pregnancy and neonatal outcomes: systematic review and meta-analysis of observational studies, $B M$ 2013;201;346-f1169.

3. McAree T, Jacobs B, Manickavasagar T, et al. Vitamin D deficiency in pregnancy - still a public health issue, Matern Child Nutr, 2013:9(1):23-30.

4. Dijkstra SH, Van Beek A, Janssen JW, et al., High Prevalence of Ditamin 1 feficiency in New borns of $H$ igh Risk Mothers, ArCh Dis Child 2007:02:750-53.

5. Finer S, Khan $\mathrm{KS}$, Hitman GA, Inadequate vitamin D status in pregnancy: evidence for supplementation, Acta Obstet Gynecol scand, 201291:2:159-63.

6. Hypponen E Powers C. Hypovitaminosis D in British adults te $45 \mathrm{y}$ : Po nation $\mathrm{C}$. predictors Am J Clin Nutr, 2007:85:860-68.

Mokdad AH, Serdula MK DietzWH, et a The Spread of the Obesity Epidemic in the United States 1991-1998, IAMA, 1999:282(16):1519-22.

8. Ogden CL, Carroll MD, Kit BK, Flegal KM, Prevalence of Obesity in the United States, 2009-2010, NCHS Data Brief January $2012 \mathrm{cdc}$.gov/nchs/data/databriefs/db82.pdf 2012

9. Bates C, Fat Britain: tackling the obesity epidemic, (Available at: Daily Mail.co.uk/health.-obesity-epidemic.html).

10. Reilly JJ, Methven E, MCDowell ZC, et al., Health consequences of obesity, Arch Dis Child, 2003;88(9):748-52. 11. Avenell A, Broom J, Brown TJ, et al., Systematic review of the for obesity and implications for health improvement, Health Technol Assess, 2004; 8(21):iii-iv, 1-182.

12. Guh DP, Zhang W, Bansback N, et al., The incidence of comorbidities related to obesity and overwoight: A systematic review and meta-analysis, BMC Public Health, 2009:9:88.

13. Holick MF, Vitamin D: importance in the prevention of cancers, type 1 diabetes, heart disease, and osteoporosis, Am I Clin Nutr, 2004;79(3):362-71.

14. Maiya S, Sullivan I, Allgrove J, et al., Hypocalcaemia and vitamin $D$ deficiency: an important but preventable cause of life threatening infant heart failure, Heart, 2008:94:581-4.

15. Mawer $E$, Davies $M$, Vitamin $D$ nutrition and bone disease in adults, Rev Endocr Metab Disord, 2001:2:153-64

16. Raja UA, McAree T, Bassett P, Sharma S, The implications of a raised maternal BMI: A DGH experience, $J$ Obstet Gynaecol 2012,32(3):247-51

17. Sebire NJ, Jolly M, Harris JP, et al., Maternal obesity and pregnancy outcome: a study of 287,213 pregnancies in London, Int J Obes Relat Metab Disord, 2001;25(8):1175-82.

18. Villamor $E$, Cnattingius $S$, Inter-pregnancy weight change and risk for adverse pregnancy outcomes: a population based risk for adverse pregnancy outcomes:
study, Lancet, 2006; $368(9542): 1164-70$

19. Chu SY, Bachman DJ, Callaghan WM, Association between Chu SY, Bach, Zno DJ, Callaghan WM, Association between N Engl J Med, 2008:358:1444-53.

20. Ehronberg HM, Durnwald CP, Catalano P, Mercer BM, The influence of obesity and diabetes on the risk for ce, the delivery, Am J Obstet Gynecol, 2004;191(3):969-74.

21. Nohr EA, Villamor $E$, Vaeth $M$, et al, Mortality in infants of obese mothers: is risk modified by mode of delivery?, Acta Obstet Gynecol Scand, 2012:91(3):363-71.

22. Catalano PM, Focus on Obesity: Obesity, insulin resistance

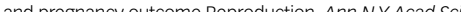
2006:1092:138-47.

23. Pittas AG, Lau J, Hu FB, Dawson-Hughes B, The role of vitamin $\mathrm{D}$ and calcium in type 2 diabetes $A$ syster 2007:92(6):2017-29.

24. Kendrick J, Targher G, Smits G, Chonchol M, 25-Hydroxwitamin D deficiency is independenty associated with cardiovasoular D deficiency is independently assoclated with cardiovascular Survey, Atherosclerosis, 2008;205(1):255-60.

25. Pittas AG, Chung M, Trikalinos T, et al., Vitamin D and Cardiometabolic Outcomes: A Systematic Review, Ann Intern Med, 2010;152(5):307-14.

26. Sung CC, Liao MT, Lu KC, Wu CC, Role of Vitamin D in Insulin Resistance, J Biomed Biotechnol, 2012;634195.

27. Belenchia $\mathrm{A}$, Anthony $\mathrm{M}$, Tosh $\mathrm{AK}$, et al., Correcting vitamin $D$ insufficiency improves insulin sensitivity in obese adolescents: a randomized controlled trial, Am J Clin Nutr. 2013:97(4):774-81.

28. Parikh SJ, Edelman M, Uwaifo Gl, et al., The Relationship between Obesity and Serum 1,25-Dihydroxy Vitamin D Concentrations in Healthy Adults, $J$ Clin Endocrinol Metab, 2004;89(3):1196-9.

29. Narvaez CJ, Matthews D, Broun E, et al., Lean Phenotype and Resistance to Diet-Induced Obesity in Vitamin D Receptor Knockout Mice Correlates with Induction of Uncoupling Protein-1in White Adipose Tissue, Endocrinology, 2009; 150:651-61.

30. Wortsman 」, Matsuoka LY, Chen TC, et al., Decreased bioavailability of vitamin D in obesity. Am 1 Clin Nutr. 2000;72:690-93.

31. Roth DE, Mahmud AA, Ragib R, et al., Pharmacokinetics of a single oral dose of vitamin D3 (70,000 IU) in pregnant and non-pregnant women, Nutr J, 2012;11:114

32. Bodnar LM, Catov JM, Roberts JM, Simhan HN, Pre-pregnancy obesity Predicts Poor Vitamin D Status in Mothers and Their Neonates, J Nutr, 2007:137(11): 2437-42.

33. Evans KN, Bulmer JN, Kilby MD, Hewison M, Vitamin D and placental-decidual function, I Soc Gynecol Investig, 2004;11(5):263-71.

34. Merewood A, Mehta SD, Chen TC, et al, Association between vitamin D deficiency and primary caesarean section, I Clin Endocrinol Metab, 2009;94:940-45.

35. Scholl TO, Chen X, Stein P. Maternal Vitamin D Status and Delivery by Cesarean Nutrients, Nutrients, 2012;4(4):319-30 Robinson CJ, Alanis MC, Wagner CL, et al., Plasma 25-hydroxyvitamin D levels in early-onset severe 25-hydroxyvitamin D levels in early-onset severe De-Regil L, Palacios C, Ansary A, et al., Vitamin D supplementation for women during pregnancy, Cochrane Database syst Rev, 2012;2:CD008873.

38. Hypponen E, Boucher B Avoidance of vitamin D deficiency in pregnancy in the Bnited Kingdom: the case for a unified aproas

apploch Deluca H, Ove 2004;80(Suppl):1689S-96S.

40. Calvo MS Whiting SI Barton CN, Vitamin D fortification in the United States and Canada: current status and data needs, Am J Clin Nutr, 2004;80(Suppl. 6):1710S-6S.

41. Holick $M$, Brinkley $N C$, Bischoff-Ferrari $H A$, et al., Evaluation, Treatment, and Prevention of Vitamin D Deficiency: an Endocrine Society Clinical Practice Guideline, I Clin Endocrinol Metab, 2011;96:1911-30.

42. Yu CK, Sykes L, Sethi M, et al., Vitamin D deficiency and supplementation during pregnancy, Clin Endocrinol (OXf) 2009;70(5):685-90.

43. O'Donnell S, Cranney A, Horsley T, et al. Efficacy of food fortification on serum 25-hydroxyvitamin D concentrations:
systematic review, Am J Clin Nutr, 2008;88:1528-34.

4. Systembock $H$, The induction of growth promoting and calcifying properties in a ration by exposure to light, Science, 1924;60:224-5

45. Cnattingius S, Villamor E, Lagerros YT, et al., High Birth Weight and obesity - a vicious circle across the generations, int Obes (Lond), 2012;36(10):1320-24. 